\title{
Os Caminhos de Hamlet no Cinema
}

\author{
Ricardo Amarante Turatti
}

O príncipe da Dinamarca segura um crânio. Observa, cuidadosamente, os restos mortais daquele que um dia foi Yorick, o bobo da corte. Dessa observação surgem questionamentos filosóficos sobre a transitoriedade da vida, que são transmitidos ao leitor por meio das palavras de William Shakespeare:

\begin{abstract}
Alas, poor Yorick! - I knew him, Horatio: a fellow of infinite jest, of most excelent fancy: he hath borne me on his back a thousand times; and now, how aborred in my imagination it is! My gorge rises at it. Here hung those lips that I have kist I know not how oft. Where be your gibes now? Your gambols? Your songs? Your flashes of merriment, that were wont to set the table on a roar? [...] (SHAKESPEARE, 2007, p. 707).
\end{abstract}

Essa imagem icônica está em Hamlet, peça que, estima-se, tenha sido escrita durante a primeira década do século XVII. Críticos e amantes de Shakespeare - os bardólatras - defendem a hipótese de a peça ter sido trabalhada durante boa parte da vida do autor, só atingindo sua forma completa nesse período de início de século (BLOOM, 2000. pp. 25-

1 Hamlet, Ato V, Cena I. “Olá, pobre Yorick! Eu o conheci, Horácio. Um rapaz de infinita graça, de espantosa fantasia. Mil vezes me carregou nas costas; e agora, me causa horror só de lembrar! Me revolta o estômago! Daqui pendiam os lábios que eu beijei não sei quantas vezes. Yorick, onde andam agora as tuas piadas? Tuas cambalhotas? Tuas cantigas? Teus lampejos de alegria que faziam a mesa explodir em gargalhadas? [...]" (SHAKESPEARE, 1997, p. 122). 
45). Juntamente com Hamlet, nessa última década e meia de produção shakespeariana, o público inglês assistiu às tragédias de maior prestígio na obra do dramaturgo, como Macbeth, Othelo e Rei Lear (HALLIDAY, 1990; HOLDEN, 2003). Todas essas tragédias trazem ao público espectador ou leitor, seja ele dos séculos XVI e XVII ou do atual, imagens e palavras marcantes. Curiosamente, a imagem de Hamlet filosofando sobre a vida diante do crânio descarnado de Yorick tem sido frequentemente ligada a outro momento da peça, o conhecido solilóquio do "ser ou não ser":

To be, or not to be, - that is the question: -

Wheter 'tis noble in the mind to suffer

The slings and arrows of outrageous fortune,

Or to take arms against a sea of troubles,

And by opposing end them? - To die, - to sleep, -

No more [...]

(SHAKESPEARE, 2007, p. 688). ${ }^{2}$

Para muitos não leitores da peça, uma cena inexistente é formada. É como se a imagem mais marcante fosse fundida com as palavras mais significativas, criando um Hamlet sintetizado. O príncipe questionando o ser ou não ser, a transitoriedade e o significado da vida, enquanto fita a caveira de Yorick tornou-se um clichê, quando se exploram temas ligados à arte dramática. Continuando a pensar no campo das imagens, podemos passar às interpretações da peça no cinema, essa fusão de som e imagem, do visto com o ouvido.

Utilizo o termo "interpretação" porque minha intenção é tratar os filmes baseados na obra de Shakespeare como uma leitura do original. Cada diretor possui sua visão particular de Hamlet, que é transmitida para a tela, resultando em uma interpretação. O fato de a maioria dos trabalhos baseados em Shakespeare contarem com uma extrema reverência pelo texto original só reforça essa ideia de que os filmes são uma obra interpretativa, uma leitura. Em algumas obras cinematográficas, o texto inclusive torna-se mais forte e mais intenso do que o fluxo de imagens. Mesmo em versões que utilizam uma ambientação mais contemporânea, como o Romeu e Julieta (1996) de Baz Luhrmann, a opção é preservar os versos contidos na peça original, e não atualizá-los para uma linguagem com um apelo mais moderno. Essa reverência indica uma vertente teórica

2 Hamlet, Ato III, Cena I. "Ser ou não ser - eis a questão. / Será mais nobre sofrer na alma / Pedradas e flechadas do destino feroz / Ou pegar em armas contra o mar de angústias - / E, combatendo-o, dar-lhe fim? Morrer, dormir; / Só isso. [...]" (SHAKESPEARE, 1997, p. 63). 
da crítica literária, que defende a existência de um universalismo na obra shakespeariana, um elemento adequado a qualquer realidade histórica, sociedade ou época. O crítico literário Harold Bloom (200o, p. 43), crente nesse princípio de universalidade, afirma: “[...] concluo ser Shakespeare não apenas o próprio cânone ocidental como, também, o cânone universal [...]".

Os escritos de William Shakespeare ganham, portanto, a estatura de cânones literários, de símbolos de excelências e de construtores da humanidade. Essa tese da universalidade e da invenção do humano empurra a análise para uma tendência à desistorização da obra, como se as peças pudessem se referir a qualquer contexto e época. Mesmo reconhecendo que as obras possuem um alcance e uma maleabilidade de leituras invejáveis, acredito que o apelo ao universal só leva a crítica a se tornar uma vertente da bardolatria, porém mais refinada e dotada de certificados acadêmicos. Esse discurso de proposição de um universalismo leva a uma sacralização da obra shakespeariana, criando uma teia de visões que chegam a atingir as constantes interpretações das peças do dramaturgo. No momento de ganharem os palcos dos teatros, ou as telas dos cinemas, enfrentam diversos olhos críticos esperando encontrar alguma "traição" à obra do Bardo. ${ }^{3}$

Alguns diretores investem na utilização do texto literal, como é o caso das versões cinematográficas de Hamlet realizadas por Laurence Olivier (1907-1989), em 1948, e por Kenneth Branagh (1960- ), em 1996. Já outros acreditam na força da adaptação, trazendo a obra shakespeariana para outros contextos e procurando mostrar que seus textos abordam problemas filosóficos presentes em diversas épocas e realidades. Um dos realizadores desse tipo de interpretação é o diretor japonês Akira Kurosawa (1910-1998), que adaptou Macbeth e Rei Lear sob os títulos de Trono manchado de sangue (1957) e Ran (1985), e conseguiu trazer à tona algumas das possibilidades mais interessantes para se transportar Shakespeare ao cinema. Trazendo essas duas tragédias para o contexto japonês, Kurosawa buscou aproximar as culturas ocidental e oriental,

\footnotetext{
3 Bardo é uma denominação utilizada em determinadas regiões da Europa para se referir a músicos e poetas, que transmitiram suas obras poéticas por meio de canções, reforçando a corrente da tradição oral. Termo presente principalmente em países como a Inglaterra e a Irlanda, a figura do bardo é tanto histórica quanto mítica. Nos países de língua inglesa, porém, o termo "The Bard" [O Bardo] é usado para se referir somente a William Shakespeare, colocando-o em um patamar de prestígio superior aos demais poetas falantes do idioma e colaborando para a mitificação de sua figura.
}

Remate de Males, Campinas-SP, v. 37, n. 1, pp. 409-427, jan./jun. 2017 
reforçando que conflitos políticos e questionamentos sobre o sentido da existência são encontrados em mais de uma realidade histórica.

Esse tipo de visão histórica e dramática não corresponde exatamente à teoria do universalismo de Bloom, mas apresenta uma ideia de que os conflitos humanos estão presentes em qualquer parte do mundo, porém assumem diferentes formas e são desencadeados pelos mais diversos motivos. Sem desprezar as particularidades históricas de cada época, o diretor japonês realiza uma condensação e uma adaptação da obra de Shakespeare, para desenvolver filmes que são interpretações do passado do Japão. Condensação pelo fato de modificar imagens e situações; adaptação por não utilizar o texto literal e modificar consideravelmente a ambientação; e interpretação por apresentar ao público espectador um estudo sobre o passado, sobre a história japonesa.

Outro exemplo desse modelo de condensação, interpretação e adaptação de Hamlet ocorre com uma produção brasileira: A herança, dirigido por Ozualdo Candeias em 1970. A trama do príncipe dinamarquês é transplantada para o cenário rural brasileiro, abordando o conflito familiar com técnica cinematográfica e escolhas estilísticas e temáticas ousadas. Há uma ausência de falas sonoras - as ações falam por si - e, como complemento, ao público só são oferecidas legendas que complementam o conteúdo e ressaltam o pensamento das personagens. O protagonista não é filho de rei, mas filho de latifundiário, que teve a terra de seu pai usurpada. O crânio que o fazendeiro do Centro-Sul do Brasil segura entre as mãos não é o de Yorick, mas o de um boi. Marcando ainda mais a ousadia temática de Candeias e o comentário aguçado sobre a situação brasileira, há o conteúdo social da obra. Os camponeses pauperizados, que circulam em torno ao latifúndio, são presenças constantes. Ao final, quando os personagens principais perecem, aparece o testamento do latifundiário Omeleto. A terra é doada aos que nela trabalham, indicando um apoio à tese da reforma agrária em plena ditadura civil-militar brasileira. O texto consagrado forma a base para um filme mudo e forte, que comenta a realidade brasileira de forma eficiente e metaforicamente refinada.

Porém, o presente artigo irá privilegiar versões que se pretendem mais próximas ao texto original e que embarcam em um menor grau de ousadia na transposição espaço-temporal de cenários. Como exemplificado com os filmes de Kurosawa e Candeias, no caso das diferentes versões cinematográficas de Hamlet, podemos encontrar condensações, adaptações e interpretações. Utilizarei como foco os filmes já citados 
anteriormente, de Olivier e de Branagh. O primeiro é, ao mesmo tempo, uma condensação e uma interpretação da peça original. Já o segundo se trata de uma interpretação, famosa por ser a única versão cinematográfica de Hamlet a utilizar o texto em sua integralidade, resultando em um filme com cerca de quatro horas de duração.

Como exemplificado pela cena do crânio de Yorick em fusão com o solilóquio do "ser ou não ser", a obra de Laurence Olivier também realiza um deslocamento condensador que modifica boa parte do conteúdo político da peça. O texto não é utilizado em sua totalidade, e as escolhas realizadas por Olivier reforçam o lado psicológico da personagem principal, ao mesmo tempo em que transformam a intriga política em uma pálida sombra do que foi descrito pelos versos de Shakespeare. Mas, antes de comentar sobre como Hamlet foi transportado ao cinema, é interessante fazer uma exposição sintética sobre o enredo da peça, de modo a contextualizar as escolhas dos diretores.

A trama se desenvolve no reino da Dinamarca, cujo trono está ocupado por Cláudio, irmão do falecido rei Hamlet. Apenas um mês após a morte do irmão, Cláudio se casa com Gertrudes, a rainha viúva, assumindo o governo dinamarquês. Esse fato perturba profundamente o jovem príncipe Hamlet, que mergulha em reflexões sombrias sobre a própria existência. Enquanto Cláudio procura consolidar seu novo reinado, enfrentando alguns problemas diplomáticos com a Noruega, os guardas do castelo são assombrados pela aparição de um espectro semelhante ao rei morto. Quando o príncipe Hamlet toma ciência desse acontecimento, ele persegue o fantasma, descobre que se trata realmente do espírito de seu pai e ouve uma revelação perturbadora. O falecido rei alega ter sido traído pelo irmão, que o assassinou porque ambicionava o trono e a rainha. Hamlet, então, jura vingança, prometendo restaurar o trono dinamarquês a quem é de direito, impedindo que continue nas mãos de um usurpador. Porém, passar do pensamento à ação é uma das maiores torturas íntimas de Hamlet. O príncipe escolhe se alienar da realidade, de modo a observar os fatos de maneira mais distanciada, e finge-se de louco, afetando diversas pessoas a seu redor, como sua amada Ofélia. Ao conviver com a pretensa loucura de Hamlet, Ofélia realmente enlouquece, buscando fugir dos horrores da realidade.

O simbolismo da loucura é algo extremamente marcante em Hamlet. Tanto o príncipe como Ofélia buscam um escapismo da realidade, mas enquanto o primeiro tenta refletir sobre o cumprimento de seu juramento 
de vingança, adiando-o, Ofélia perde as estruturas de sua vida ao perceber que o homem de quem se julgava noiva não está consciente de seus deveres. O destino dos dois é o mesmo: a morte. Ofélia se suicida e Hamlet, quando coloca em ação sua vingança longamente arquitetada, é envenenado pelo rei, em uma cena final que leva à morte grande parte das personagens da peça.

Em um duelo com Laertes, irmão de Ofélia, Hamlet descobre que a espada de seu adversário foi envenenada a mando do rei. Dessa descoberta vem uma explosão de violência e envenenamentos. Hamlet é ferido pela espada mortal de Laertes e o fere com ela. A rainha Gertrudes bebe, por engano, um vinho que o rei Cláudio havia envenenado. E o príncipe Hamlet, cumprindo sua promessa de vingança, assassina o rei usurpador. Porém, morrendo, deixa o trono vazio. Sua vingança levou à destruição de uma família real.

Nesse ponto, em que a história se aproxima do desfecho, a Dinamarca é invadida pelo exército norueguês, liderado por Fortinbrás. Alguns anos antes do enredo da peça ter sido iniciado, o rei Hamlet havia tomado, após uma batalha, territórios noruegueses, recebendo tributos desse outro país nórdico. Com a morte do rei, o príncipe norueguês, Fortinbrás, reivindica os territórios tomados. Cláudio, lidando de forma inapta com a questão, abre caminho para a invasão da Dinamarca, anunciada ao longo de toda a peça e concretizada na última cena do último ato. A peça termina nesse ponto, com as palavras de Fortinbrás:

Let four captains

Bear Hamlet, like a soldier, to the stage;

For he was likely, had he been put on,

To have proved most royally: and, for his passage,

The soldiers' music and the rites of war

Speak loudly for him. -

Take up the bodies: - such a sight as this

Becomes the field, but here shows much amiss. -

Go, bid the soldiers shoot

(SHAKESPEARE, 2007, p. 713). ${ }^{4}$

\footnotetext{
4 Hamlet, Ato V, Cena II. “Que quatro capitães / Carreguem Hamlet como soldado para um cadafalso. / É evidente que, se houvesse reinado, / Seria um grande rei. / Que a grande música marcial e os ritos guerreiros / Falam alto por ele, / Na sua partida. / Levai os corpos. / Esta cena final / Convém mais ao campo de batalha. Aqui vai mal. / Ide! Que os soldados disparem." (SHAKESPEARE, 1997, p. 140).
}

Remate de Males, Campinas-SP, v. 37, n. 1, pp. 409-427, jan./jun. 2017 
Esseenredo foi interpretado, na maioria das versões para outras mídias, como uma trama de conteúdo psicológico, um debate íntimo entre o dever e a consciência e uma complexa história de vingança. O ciúme obsessivo que Hamlet sente de Gertrudes, sua mãe, pode até ser aproximado do complexo de Édipo freudiano, sendo que a obra de Shakespeare é citada por Freud em $A$ interpretação dos sonhos (FREUD, 2001, pp. 153-154), lado a lado com Édipo rei, de Sófocles. Porém, é necessário lembrar que essa obra de Freud data de 1900, época em que as explorações do aspecto psicológico em obras de ficção foram incrivelmente mais valorizadas do que no início do século XVII, período que presenciou o auge do teatro shakespeariano. Mesmo que exista um conteúdo psicológico fortíssimo no texto original, característica não costumeira entre os autores da época, não se pode desprezar o enfoque político da peça.

Essa dimensão está presente em dois fatores principais: a corrupção do rei Cláudio e a invasão de Fortinbrás, duas características que levam ao fim de uma dinastia, representada pela família de Hamlet, e à instauração de uma nova casa real, proveniente do norueguês Fortinbrás. A inépcia de Cláudio para conduzir os assuntos internos de seu governo, após ter usurpado o trono de seu irmão - que é lembrado como um rei justo e um bom governante - leva também a dissensões externas. Essa incompetência, aliada à corrupção pessoal e política de Claúdio e à demora de Hamlet em tomar uma posição diante da crise, permite que o exército de Fortinbrás invada a Dinamarca e instaure uma nova casa real.

A peça não fala, portanto, somente da dimensão particular de suas personagens, dos aguilhões que atormentam a alma de Hamlet, mas também da dimensão política, tecendo o pungente retrato de uma dinastia em declínio. É exatamente a personagem de Fortinbrás que representa a chave para essa visão política, tão importante em diversas obras de Shakespeare (HELIODORA, 2005). Excluir o norueguês de uma interpretação da peça implica, quase sempre, diminuir o alcance temático dela. Seja com a intenção de diminuir a extensão do texto ou de evitar uma diversidade muito grande de assuntos, alguns intérpretes preferem limar a invasão norueguesa de suas versões.

Laurence Olivier ignora Fortinbrás em sua sombria e intimista versão de Hamlet. O enfoque do diretor é o lado psicológico da personagem principal. As demais personagens interessantes para uma abordagem psicológica, como Ofélia e Cláudio, aparecem de forma menos destacada. Todososdetalhescontidos notextoshakespearianosãodiminuídospara dar 
lugar à impressionante personalidade e intelecto de Hamlet, interpretado pelo próprio diretor. $\mathrm{O}$ impacto dessa condensação interpretativa da peça de Shakespeare foi consideravelmente grande entre a crítica e o público dos anos 1940. A obra foi laureada com o prêmio de melhor filme entregue pela Academia de Artes e Ciências Cinematográficas de Hollywood, o popular Oscar. No momento, Laurence Olivier aparecia como o primeiro grande intérprete de Shakespeare nas telas do cinema. Intérprete não apenas no sentido de ator, mas de estudioso da obra shakespeariana e diretor de filmes marcantes baseados na produção do Bardo. O segundo ator/diretor com um conhecimento destacado das peças do dramaturgo inglês a se consagrar no cinema seria exatamente Kenneth Branagh, diretor do Hamlet de 1996, outro dos filmes a serem analisados neste artigo. Branagh já foi chamado de herdeiro de Olivier e, no filme Sete dias com Marilyn, de 2011, levou adiante a tarefa de interpretá-lo.

Alguns anos antes do lançamento de Hamlet, em 1944, o inglês Olivier já havia dirigido uma suntuosa versão de uma das peças históricas de Shakespeare: Henrique V. Ao contrário da fotografia em preto e branco soturna adotada para a filmagem da história do príncipe da Dinamarca, Henrique V ganha as telas com um colorido por vezes excessivo e com opções interpretativas destinadas a dialogar com a atmosfera teatral do texto original. Algumas das escolhas para discutir a teatralidade da história funcionaram, como as cenas iniciais, que levam o espectador ao palco do Globe, o teatro onde parte das peças de Shakespeare foi encenada. Essa é uma forma interessante de metalinguagem, que firmou Olivier como um intérprete capaz de trazer novas visões para o que seria traduzir Shakespeare para o cinema. ${ }^{5}$

Parte desses avanços foram utilizados em Hamlet, como os solilóquios que não são ditos, mas narrados em off, como se o príncipe da Dinamarca

5 Kenneth Branagh também realizou sua versão de Henrique V, em 1989, e uma análise comparativa entre seu filme e o de Olivier geraria um estudo à parte. Branagh consegue superar diversas dificuldades de filmagem, mantendo o texto idêntico ao original, mas adotando escolhas cinematográficas que dão a seu filme uma força dramática muito superior à da peça, que em diversos momentos é arrastada e enfadonha. Outro detalhe interessante a ser notado: enquanto a peça de Shakespeare e o filme de Olivier são exaltações ao poderio bélico e à força nacional da Inglaterra - o filme foi lançado em 1944, em plena Segunda Guerra Mundial -, a obra de Branagh traz uma visão amarga e antibélica. Lembrando que Olivier condensa o texto, enquanto Branagh o utiliza integralmente. Isso demonstra o poder de uma interpretação, já que mesmo não alterando a peça original, Branagh oferece novas possibilidades de contar a história, enquanto Olivier a condensa e interpreta para tecer um comentário político sobre a situação da Europa durante a Segunda Guerra Mundial. 
permitisse ao público ouvir seus pensamentos. Mas é inevitável, principalmente ao se analisar o filme vários anos após o seu lançamento, encontrar uma falta de dinamismo dramático e uma atmosfera de teatro filmado. Acima de tudo, nota-se o foco exagerado na personalidade de Hamlet, escolha que fica entre a admiração extremada pela personagem e a exaltação ególatra, realizada por Olivier, de seu próprio trabalho como ator e diretor shakespeariano. E novamente insisto: ao ignorar Fortinbrás, as possibilidades de exploração da peça diminuem, fazendo com que o intérprete corra o risco de transformar um enredo riquíssimo em uma sessão de análise anacrônica e repetitiva. O particular, em Shakespeare, tem relação direta com o público, a individualidade com a política. Laurence Olivier, condensando cenas, resumindo o texto e interpretando passagens com um viés unicamente psicológico, acaba por reduzir o alcance de seu filme.

No referente ao estilo cinematográfico, há algumas opções interessantes, apesar das locações fechadas e sombrias que, ao mesmo tempo em que ressaltam o labirinto em que se encontra a mente de Hamlet, transmitem ao público uma sensação de claustrofobia e um clima afetadamente teatral. Russel Jackson, fazendo uma síntese da trajetória das peças de Shakespeare nas telas do cinema, realiza uma interpretação do filme de Olivier, ressaltando as escolhas estilísticas que mais chamam a atenção:

[...] Olivier's own next step in Shakespearian filmmaking was Hamlet (1948), a neo-gothic psychological study which strips away the political material from the play and announces itself in the opening moments as "the story of a man who could not make up his mind”. [...] Roger Furse's designs for this almost entirely studio-bound film create a castle of dark recesses and archways and vertiginous staircases [...] The shadowy black-and-white photography and empty, mostly stone-walled chambers and passages (there is hardly any furniture) have been said to evoke both the psychological intensity of film noir and the mannerisms of German 1920s expressionist film (JACKSON, 2001, pp. 220-221). ${ }^{6}$

6 "[...] O passo seguinte de Olivier no cinema shakespeariano foi Hamlet (1948), um estudo psicológico neogótico que despe a peça de seu material político e se anuncia nos momentos iniciais como 'a história de um homem que não conseguia se decidir'. [...] Os desenhos de Roger Furse para essa obra filmada quase inteiramente em estúdio criaram um castelo de negros recessos e arcadas e escadarias vertiginosas [...] A sombria fotografia em preto e branco e os vazios, quase sempre murados, aposentos e passagens (quase não há mobília) têm sido relacionados com a evocação tanto da intensidade psicológica do film noir quanto dos maneirismos do cinema expressionista alemão dos anos 1920" (tradução nossa).

Remate de Males, Campinas-SP, v. 37, n. 1, pp. 409-427, jan./jun. 2017 
Quer evoque ou não esses estilos particulares de cinema, o Hamlet de Olivier defende um estilo próprio de se filmar Shakespeare. Esse é o maior mérito do filme, apesar de todas as suas falhas e do efeito teatral que esse estilo possa causar. Uma proposição formal nova quase sempre causa um efeito marcante no cinema, seja esse efeito positivo ou negativo. Não se pode negar, então, o marco que a obra de Olivier representou para o cinema e para as interpretações de Shakespeare em outras mídias. Hamlet e o conjunto de filmes shakespearianos dirigidos e protagonizados pelo artista britânico ${ }^{7}$ simbolizam um conjunto de obras cinematográficas que impulsionou a presença constante de Shakespeare no cinema, consagrando Olivier como o primeiro grande intérprete cinematográfico do Bardo e como um ator que levou a dramaturgia shakespeariana para além do palco. Com a reação positiva do público e da crítica da época, e com o recebimento do Oscar de Melhor Filme, Hamlet foi um filme decisivo para o aparecimento de diferentes versões das peças do dramaturgo inglês na sétima arte.

\section{II}

Além das duas versões a serem analisadas com mais detalhes neste artigo, e das produções fora do âmbito da língua inglesa mencionadas anteriormente, existem outros trabalhos centrados em Hamlet dignos de atenção. Destacarei alguns, de modo a ilustrar mais possibilidades para a interpretação da peça no cinema. Seguindo as categorias já exploradas anteriormente, as de interpretação, condensação e adaptação, podemos identificar como os filmes a serem agora citados podem se encaixar em algumas delas. Em certos casos, uma obra pode se enquadrar em todas. É o caso do Hamlet dirigido por Michael Almereyda em 2000, uma versão moderna da peça, que se passa em uma grande empresa, a Denmark Corporation, ao invés de um reino. O texto de Shakespeare é interpretado sem alterações, mas não na íntegra, e são utilizados deslocamentos que

\footnotetext{
7 Uma lista completa de todos os filmes baseados em Shakespeare que contaram com a participação de Laurence Olivier: Como gostais (As you like it, 1936), Henrique V (Henry $V$, 1944), Hamlet (1948), Ricardo III (Richard III, 1955), Otelo (Othello, 1965), O mercador de Veneza (The merchant of Venice, 1973, filme feito para a televisão) e Rei Lear (King Lear, 1983, filme feito para a televisão). Dentre as obras constantes na lista, apenas três foram dirigidas por Olivier, a saber: Henrique V, Hamlet e Ricardo III. O ator/diretor também participou, sem receber créditos, da narração da versão em inglês de Romeu e Julieta, de Franco Zeffirelli.
} 
condensam a história. Ao transportar a história do herdeiro do reino da Dinamarca para o herdeiro de uma grande potência empresarial, Almereyda, que também é responsável pelo roteiro do filme, parece estar afirmando a pretensa universalidade de Shakespeare. Já que a trama existe em função de intrigas palacianas, ela também funcionaria no ambiente empresarial capitalista, seguindo essa lógica do universalismo. Porém, esse transporte de períodos só realça o fato de que dizer que Shakespeare é universal, ou até mesmo afirmar que algo seja universal, é uma proposição falha. Nada escapa de seu momento histórico, de sua própria historicidade e dos discursos que perpassam esse determinado período (FOUCAULT, 2009, p. 70), juntamente com sua cultura e suas ideias. É por isso que ouvir Hamlet, em uma interpretação extremamente fraca de Ethan Hawke, declamar "to be or not to be" em uma locadora de vídeo traz um impacto quase nulo. O estranhamento é maior do que a inovação, e esse momento tão conhecido e louvado é esvaziado de boa parte de sua densidade.

Uma pergunta importante a ser levantada éa seguinte: já que o diretor / roteirista desejou realizar uma versão inovadora de Shakespeare, porque manter o texto como foi escrito pelo poeta, apenas condensando-o? É uma escolha contraditória a que é expressa no Hamlet de 2000, similar à que ocorreu na versão de Baz Luhrmann para Romeu e Julieta. Ao mesmo tempo em que se propõe uma ambientação contemporânea, jovem, por vezes até com aparência de videoclipe, o texto é preservado, como se fosse um cânone sagrado. São filmes que expressam o encontro de uma tentativa de inovar e de ser irreverente com uma reverência profunda pela obra de Shakespeare, o que resulta em obras sem personalidade e até em um certo conservadorismo cinematográfico. Tanto o Romeu e Julieta de 1996 quanto o Hamlet de 2000 parecem uma colcha de retalhos mal costurada, que só reforçam o equívoco que existe ao se dizer que o dramaturgo inglês escreveu algo universal.

Em 1990, o italiano Franco Zeffirelli, conhecido pela sua versão de Romeu e Julieta (1968), lançou seu Hamlet, estrelado por Mel Gibson. A principal proposta do diretor era realizar uma interpretação mais cinematográfica, de modo a atingir uma fatia maior de público. Para isso, condensou o texto da peça e retirou boa parte de seus aspectos políticos. Mas, ao contrário do que conseguiu Olivier em 1948, Zeffirelli não imprime em sua obra a mesma concentração psicológica, seja pela direção vaga que se concentra apenas nos aspectos estéticos - seja pela interpretação totalmente monótona e inexpressiva de Mel Gibson. O fator edipiano da 
relação entre Hamlet e sua mãe - interpretada por Glenn Close - é elevado exponencialmente, mas o que aparece na tela é somente uma sombra dos aspectos psicológicos e filosóficos do texto shakespeariano. A única imagem marcante do filme é a dos olhos constantemente arregalados de Gibson, assombrando essa condensação / interpretação pálida e com falta de identidade artística e dramática. Zeffirelli subestimou seu público, imaginando que ele não estaria preparado para experimentar Shakespeare em toda sua densidade, ao mesmo tempo em que superestimou a si próprio, não conseguindo realizar a condensação planejada.

Uma das utilizações mais curiosas de Hamlet ocorreu em um desenho animado dos estúdios Disney: O rei leão, de 1994. Shakespeare não é creditado no filme, mesmo que o esqueleto do enredo seja diretamente derivado de sua peça. Como o Hamlet de 2000, O rei leão é uma interpretação/condensação/adaptação da peça, e pouco lembrado enquanto tal, mesmo sendo uma das versões mais ricas da história, principalmente pelo fato de criar e inovar. O desenho animado utiliza a história do príncipe dinamarquês como trampolim para um enredo sobre identidade, responsabilidade e vingança.

Dirigido por Roger Allens e Rob Minkoff, O rei leão toma o enredo da peça shakespeariana como base e desenvolve uma história toda própria. Os versos de Shakespeare não estão lá, nem a mesma sequência de eventos, sendo essa uma das versões mais radicais de todas as que já ganharam as telas. A condensação feita não é apenas uma redução do texto ou um deslocamento de cenas, mas sim um roteiro totalmente novo, utilizando elementos psicológicos e políticos trabalhados por Shakespeare. O fratricídio continua presente, e a alienação do príncipe herdeiro também. Mas agora eles são interpretados por animais, por leões que possuem uma corte e uma família real na savana africana. Diferentemente de Hamlet, o protagonista Simba presencia a morte de seu pai, o rei Mufasa, e é convencido pelo tio Scar a fugir. E é Scar, irmão do rei e também seu assassino, que inicia um governo desastroso, desorganizando a cadeia alimentar, já que permite a entrada no reino de hienas vorazes, aspecto do filme que também funciona como uma lamentável mensagem racista e anti-imigração. Enquanto isso, o príncipe Simba se exila, adotando uma filosofia de vida diferente. Quem o convence a voltar e a reassumir sua responsabilidade como herdeiro do trono é, como no texto de Shakespeare, o espírito de seu pai. Não se deve deixar de lado o fato de sempre ser somente o protagonista que conversa com o fantasma do rei 
falecido, e essa observação cabe tanto à peça de Shakespeare quanto a $O$ rei Leão.

Encontram-se, portanto, convergências e divergências com Hamlet, o que só torna a obra mais rica. O exílio de Simba, assim como a loucura fingida de Hamlet, é um estado de alienação, um adiamento da ação. Mas, enquanto em $O$ rei leão o príncipe busca esquecer a brutalidade da morte do pai, em Hamlet a personagem-título se aprofunda cada vez mais na monomania da vingança, que expressa o desejo de um fantasma que só ele mesmo viu e ouviu. As diferenças continuam, criando paralelos interessantes e resultando em uma verdadeira adaptação. O enredo criado por Shakespeare encontra-se condensado no roteiro escrito por Irene Mecchi, Jonathan Roberts e Linda Woolverton. Ao mesmo tempo, a obra do poeta inglês aparece adaptada, com modificações expressivas que resultam em uma interpretação, em outra possibilidade para o desenvolvimento dos temas contidos no texto original. $\mathrm{O}$ filme tornouse um clássico, trazendo diferenças marcantes na forma de tratamento dramático dado a temas como a morte e a violência pelas demais obras do estúdio Disney. Desde 1942, com Bambi, um desenho animado do estúdio não trazia uma morte chocante de uma das personagens principais. Possuindo essa estatura de clássico, o filme é pouco lembrado como uma interpretação de Shakespeare, mesmo sendo uma das versões mais interessantes e competentes de Hamlet, no sentido cinematográfico e dramático do termo.

Dois anos após o lançamento de O rei Leão, em 1996, Kenneth Branagh apresentaria a sua versão de Hamlet, um projeto quase megalomaníaco. Com o título Hamlet de William Shakespeare, agora a peça seria filmada com seu texto integral e em 7omm, o maior tamanho de filme disponível, pouco utilizado desde os anos 6o. O filme de Branagh se enquadra apenas na categoria de interpretação, já que não condensa a peça, nem a adapta. O cenário e os figurinos escolhidos remetem ao século XIX, fato que não caracteriza o filme como adaptação, já que o contexto histórico e político continuam inalterados.

O irlandês Branagh é considerado o segundo grande intérprete de Shakespeare no cinema, ${ }^{8}$ uma espécie de herdeiro de Laurence Olivier.

8 Como fizemos no caso de Olivier, segue aqui uma lista completa dos filmes baseados em Shakespeare que contaram com a presença de Kenneth Branagh: Henrique V (Henry $V$, 1989), Muito barulho por nada (Much ado about nothing, 1993), Othelo (1995), Hamlet (1996), Love's labour's lost (200o) e As you like it (2006). Dentre esses seis filmes, Branagh não foi responsável apenas pela direção de Othelo, no qual interpretou o vilão Iago, sendo Remate de Males, Campinas-SP, v. 37, n. 1, pp. 409-427, jan./jun. 2017 
Ao contrário de seu antecessor, Branagh escolhe para seu filme cenários luminosos e ambientes amplos, gerando um contraste brutal com os recantos sombrios do filme de 1948. As opções adotadas por Branagh, tanto como diretor quanto como autor do roteiro, demonstram um respeito imenso pela obra de Shakespeare e pela versão de Olivier, sem, contudo, cair em uma reverência que empobreceria sua obra. O resultado final obtido por Branagh acaba por ser a versão mais complexa e fascinante de Hamlet já realizada.

Ao contrário do que ocorreu em outros filmes do diretor, como Love's labour's lost, a interpretação não veio acompanhada de uma adaptação conceitual. A adoção de figurinos e cenários oitocentistas não altera em nível algum o significado do filme. O que surge como diferencial são os ambientes amplos e luminosos, com uma fotografia que só adota tons soturnos em ambientes externos, como na cena do cemitério ou do colóquio entre Hamlet e o fantasma de seu pai. Já os interiores, que no filme de Olivier, mais notadamente, eram sempre opressivos e escuros, na versão de Branagh são totalmente iluminados, sendo que alguns ambientes são espelhados, o que só aumenta a noção de espaço.

A manutenção da integralidade do texto, ao invés de deixar o filme preso à peça, surpreendentemente oferece alternativas de interpretação e cenas ganham vida de forma diferente de como haviam sido encenadas anteriormente. $\mathrm{O}$ aspecto político está totalmente incluso. Fortinbrás invade a Dinamarca e, para reforçar a ideia do fim de uma dinastia, Branagh conclui seu filme com uma imagem notável pela sua força. Após as falas finais de Fortinbrás, o corpo de Hamlet é carregado pelos quatro capitães designados pelo príncipe norueguês. Logo em seguida, vemos a estátua do pai de Hamlet, localizada nos portões do palácio de Elsinore, ser derrubada pelos soldados noruegueses. É uma cena que transmite, de forma clara, o comentário sobre o declínio do poder de uma casa real. Quando a estátua representativa da dinastia Hamlet vem ao chão, o filme também atinge seu final.

Além do comentário político, a psicologia e a interioridade das personagens são também exploradas à exaustão, em todos os 242 minutos da película. Um exemplo dessa profundidade de interpretação é a realização da cena do solilóquio do "ser ou não ser". Hamlet, interpretado por Branagh, pronuncia os famosos versos diante de um espelho. Em um 
primeiro plano de interpretação, podemos dizer que o príncipe pronuncia um discurso reflexivo sobre a incerteza da vida tendo como espectador sua própria imagem. É um monólogo dirigido a si mesmo, à sua intimidade. Porém, momentos antes dos versos serem pronunciados, o rei Cláudio e seu conselheiro Polônio escondem-se atrás do espelho, em uma passagem secreta. A passagem é espelho de um lado, vidro de outro. Dessa forma, o rei e Polônio ouvem e veem todo o discurso de Hamlet, estabelecendo um segundo plano interpretativo. Uma questão surge: Hamlet sabia que possuía espectadores ou não? Caso soubesse, provavelmente mediria o que dizer e continuaria a fingir sua loucura. Caso não soubesse, aquele seria o momento de refletir sobre seus pensamentos e dúvidas mais íntimos. O que nos faz pensar: Cláudio e Polônio ouviram essa reflexão intimista ou presenciaram Hamlet interpretando um príncipe louco? Essa é apenas uma das cenas que estabelecem essas diversas camadas de complexidade e de caminhos interpretativos. A questão da virgindade de Ofélia, da revolta de Laertes e da metalinguagem presente na cena dos atores de teatro dão origem a momentos de impacto, dramaticidade e exploração psicológica e política. Momentos esses que se perderiam em uma interpretação que condense o texto, ou que se mantenha muito reverente a ele, limitando-o.

Kenneth Branagh, levando adiante sua produção exageradamente ambiciosa, consegue contornar e superar os problemas encontrados por outros intérpretes. É preciso dizer que, mesmo sendo a versão mais completa e complexa de Hamlet nas telas de cinema, o filme poderia ter se desencaminhado muito facilmente. A ambição de Branagh só não é chamada de megalomania porque seu resultado é um filme de qualidades ímpares na história do cinema. Mas existem excessos como a filmagem em 70mm, ${ }^{9}$ as imensas somas de dinheiro gastas com a produção e o extenso elenco internacional, que conta com atores célebres em papéis pequenos. No concernente ao último item, parece absurdo escalar atores como Jack Lemmon e Gerard Depardieu para papéis com pouquíssimas falas como os de Marcelo e Reinaldo, respectivamente. Mas, ao mesmo tempo em

9 Tecnicamente, a utilização da bitola de 7omm resultou em um esplendor cinematográfico poucas vezes atingidos no cinema nas últimas décadas. $O$ ponto negativo é que diversas salas de cinema de menor porte não eram adequadas à exibição desse tamanho de filme, fazendo com que o Hamlet de Kenneth Branagh fosse convertido para o mais usual tamanho de $35 \mathrm{~mm}$, ou que simplesmente não fosse exibido. Nos cinemas brasileiros, por exemplo, o filme estreou somente em 1997, em versão reduzida com duração aproximada de 150 minutos, quase metade da duração original. No momento do lançamento em vídeo, a versão integral foi disponibilizada.

Remate de Males, Campinas-SP, v. 37, n. 1, pp. 409-427, jan./jun. 2017 
que esses atores são sub-aproveitados, Kate Winslet cria uma Ofélia com uma complexidade única no cinema, já que a personagem quase sempre é apresentada como uma jovem ingênua e tola. Outras grandes interpretações são as de Derek Jacobi, com seu cruel e inseguro Cláudio, e a de Julie Christie, no papel da rainha Gertrudes. O próprio Branagh entrega um Hamlet multifacetado e convincente. Criticar a duração do filme é ser contraditório, já que não seria possível filmar o texto integral, que considero uma das virtudes da obra de Branagh, em um tempo muito menor do que os 242 minutos gastos.

São todas essas qualidades, juntamente com esses excessos e quaseexcessos, que fazem de Hamlet de William Shakespeare o caminho mais criativo e interessante tomado pela peça de Shakespeare nas telas do cinema. Provavelmente o público espectador de cinema ainda presenciará novas versões e interpretações de Hamlet, que, inevitavelmente, serão comparadas com versões anteriores e com o texto original. Alguns dos parâmetros comparativos utilizados serão, quase certamente, os filmes dirigidos e interpretados por Laurence Olivier e Kenneth Branagh.

Partindo de um corpo de obras escrito nos séculos XVI e XVII, explorando os campos do teatro e da literatura até chegar a essa forma de arte tão presente no século XX - e também no XXI - que é o cinema, o que podemos perceber é um grande diálogo cultural e artístico. As releituras da obra de Shakespeare permitem ressignificações de seus enredos e personagens, marcando um processo histórico e também característico da construção literária. Explorar leituras cinematográficas de Hamlet é apenas uma folha de uma imensa árvore cultural que é o estudo e a leitura de William Shakespeare. Trabalhar com Shakespeare é sempre um ponto de partida. Porém, uma árvore não é um universo. Talvez ele esteja confinado na casca de uma noz, como nos diz o triste príncipe da Dinamarca. Precisamos estar atentos para a intercessão de tempo e espaço, para a malha discursiva que permite o firmamento das raízes dessa árvore frondosa.

\section{REFERÊNCIAS BIBLIOGRÁFICAS}

BLOOM, Harold. Shakespeare: a invenção do humano. Trad. José Roberto O’Shea. Rio de Janeiro: Objetiva, 2000. 
FOUCAULT, Michel. A ordem do discurso: aula inaugural no Collège de France, pronunciada em 2 de dezembro de 1970. 18a ed. Trad. Laura Fraga de Almeida Sampaio. São Paulo: Edições Loyola, 2009.

FREUD, Sigmund. A interpretação dos sonhos. Trad. Walderedo Ismael de Oliveira. Rio de Janeiro: Imago, 2001.

HALLIDAY, Frank Ernest. Shakespeare. Trad. Bárbara Heliodora. Rio de Janeiro: Jorge Zahar, 1990.

HELIODORA, Bárbara. O homem político em Shakespeare. Rio de Janeiro: Editora Agir, 2005 .

HELIODORA, Bárbara. Falando de Shakespeare. 2ª ed. São Paulo: Perspectiva, 2007.

HOLDEN, Anthony. Shakespeare. Trad. Beatriz Horta. Rio de Janeiro / São Paulo: Ediouro, 2003 .

JACKSON, Russel. Shakespeare and the Cinema. In: GRAZIA, Margreta de \& WELLS, Stanley (ed.). The Cambridge Companion to Shakespeare. Cambridge: Cambridge University Press, 2001, pp. 217-233.

SHAKESPEARE, William. Hamlet. Trad. Millôr Fernandes. Porto Alegre: L\&PM, 1997.

SHAKESPEARE, William. Complete Works. London: Wordsworth, 2007.

\section{FILMOGRAFIA}

A HERANÇA. Direção de Ozualdo Candeias. Produção de Ozualdo Candeias. Brasil, Longfilm, 1970. Disponível em: <https://www.youtube.com/ watch?v=w3MH1UaPykE>. Acesso em: 17 fev. 2017.

AS YOU like it. Direção de Kenneth Branagh. Produção de Kenneth Branagh, Judy Hoffund e Simon Moseley. Estados Unidos, HBO Films / Reino Unido, BBC Films, Shakespeare Film Company, 2006. DVD.

BAMBI. Direção de James Algar, Samuel Armstrong, David Hand, Graham Heid, Bill Roberts, Paul Satterfield e Norman Wright. Produção de Walt Disney. Estados Unidos, Walt Disney Productions, 1942. DVD.

COMO GOSTAIS. Direção de Paul Czinner. Produção de Paul Czinner e Joseph M. Schenk. Reino Unido, Inter-Allied, 1936. DVD.

HAMLET. Direção de Laurence Olivier. Produção de Reginald Beck, Anthony Bushell e Herbert Smith. Reino Unido, Two Cities Film, 1948. DVD.

HAMLET. Direção de Franco Zeffirelli. Produção de Bruce Davey e Dyson Lovell. Estados Unidos, Sovereign Pictures, Warner Bros., Nelson Entertainment / Inglaterra, 
Carolco Pictures, Icon Entertainment International, Icon Productions / França, Canal +, Marquis, 1990. DVD.

HAMLET DE William Shakespeare. Direção de Kenneth Branagh. Produção de David Barron. Reino Unido, Castle Rock Entertainment / Estados Unidos, Turner Pictures, Fishmonger Films, 1996. DVD.

HAMLET. Direção de Michael Almereyda. Produção de Jason Blum, Andrew Fierberg, Callum Greene, Amy Hobby e John Sloss. Estados Unidos, Double A Films, 2000. DVD.

HENRIQUE V. Direção de Laurence Olivier. Produção de Dallas Bower e Laurence Olivier. Reino Unido, Two Cities Films, 1944. DVD.

HENRIQUE V. Direção de Kenneth Branagh. Produção de Bruce Sharman. Reino Unido, Renaissance Films, BBC, Curzon Film Distributors, 1989. DVD.

LOVE'S LABOUR'S lost. Direção de Kenneth Branagh. Produção de David Barron e Kenneth Branagh. Reino Unido, Arts Council of England, Shakespeare Film Company / França, StudioCanal / Estados Unidos, Pathé Pictures International, Intermedia Films, Miramax, 200o. DVD.

MUITO BARULHO por nada. Direção de Kenneth Branagh. Produção de Kenneth Branagh, Stephen Evans e David Parfitt. Reino Unido, BBC Films, Renaissance Films / Estados Unidos, American Playhouse Theatrical Films, 1993. DVD.

O MERCADOR de Veneza. Direção de John Sichel. Produção de Cecil Clarke e Lorna Mason. Reino Unido, Associated Television, National Theatre, 1973. Disponível em: <https://www.youtube.com/watch?v=7IYsPPaZNRo>. Acesso em: 17 fev. 2017.

O REI leão. Direção de Roger Allens e Rob Minkoff. Produção de Alice Dewey e Don Hahn. Estados Unidos, Walt Disney Pictures,1994. DVD.

OTELO. Direção de Stuart Burge. Produção de John Brabourne, Richard B. Goodwin e Anthony Havelock-Allan. Reino Unido, BHE Films, National Theatre of Great Britain Production, 1965. DVD.

OTHELO. Direção de Oliver Parker. Produtor de David Barron e Luc Roeg. Estados Unidos, Dakota Films, Imminent Films Production / Reino Unido, Castle Rock Entertainment, 1995. DVD.

RAN. Direção de Akira Kurosawa. Produção de Masato Hara, Hisao Kurosawa e Serge Silberman. Japão, Herald Ace, Nippon Herald Films / França, Greenwich Film Productions, 1985. DVD.

REI LEAR. Direção de Michael Elliot. Produção de David Plowright. Reino Unido, Granada Television, 1983. DVD. 
RICARDO III. Direção de Laurence Olivier. Produção de Laurence Olivier e Alexander Korda. Reino Unido, London Film Productions, 1955. DVD.

ROMEU E Julieta. Direção de Franco Zeffirelli. Produção de John Brabourne, Richard B. Goodwin e Anthony Havelock-Allan. Reino Unido, BHE Films/ Itália, Verona Produzione, Dino de Laurentiis Cinemaografica, 1968. DVD.

ROMEU E Julieta. Direção de Baz Luhrman. Produção de Baz Luhrman e Gabriella Martinelli. Estados Unidos, Bazmark Films, Twentieth Century Fox Film Corporation, 1996. DVD.

SETE DIAS com Marylin. Direção de Simon Curtis. Produção de David Parfitt e Harvey Weinstein. Reino Unido, BBC Films, Lipsync Productions, UK Film Council / Estados Unidos, Weinstein Company, Trademark Films, 2011. DVD.

TRONO MANCHADO de sangue. Direção de Akira Kurosawa. Produção de Akira Kurosawa e Sojiro Motoki. Japão, Toho Company, Kurosawa Production Co., 1957. DVD. 